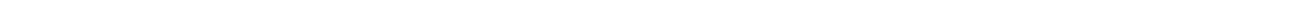

\title{
Deaths during apprehensions of agitated persons. A review of proposed pathophysiological theories.
}

\author{
Fredrik Tamsen*, M.D., M.Sc. and Ingemar Thiblin, M.D., Ph.D., Professor
}

Forensic Medicine, Department of Surgical Sciences, Uppsala University, Box 1024, 75140 Uppsala, Sweden

* fredrik.tamsen@surgsci.uu.se

\begin{abstract}
The pathophysiology of sudden death during apprehension remains largely unclear. The most frequently discussed mechanisms are excited delirium, positional asphyxia, metabolic acidosis, acute and chronic drug abuse, and autonomic instability. As in most areas of forensic medicine, much of the knowledge comes from case reports, which are of little use in understanding causality. Experimental studies of some aspects have been performed, and they show somewhat divergent results and interpretations. The aim of this review is to summarize the different proposed theories, and to point out important issues for further research.
\end{abstract}

Keywords:

excited delirium, positional asphyxia, acidosis, sudden death

\section{INTRODUCTION}

A rare event during the apprehension of agitated persons is the sudden death of the apprehended. It is not uncommon for the people who carried out the apprehension to be accused of an excess use of force, thereby causing the death. In the last two decades, there has been an intense debate about the pathophysiology of these deaths. The deaths are of course traumatizing for the decedent's family, and they are also traumatizing for the people involved in the apprehension. Since the people carrying out the apprehension are often police officers, an investigation of the circumstances and the cause of death are important to maintain the public's trust in police authorities. Forensic pathologists play a key role in these investigations. In order to make good assessments, they need solid scientific ground to stand upon. Many issues related to these deaths have been thoroughly debated, but there is no consensus about the underlying pathophysiology. There is sometimes a tendency toward polarization around this issue in the research community, possibly due to the important legal consequences of the pathologist's assessment, and to the somewhat weak scientific basis of the proposed pathophysiological mechanisms.

\section{EPIDEMIOLOGY}

In a prospective, web-based, open-source surveillance of unexpected arrestrelated deaths in the USA, 162 cases were identified during a 12-month period in 2004-2005 [1]. Given that the population in the USA was approximately 293 million in 2004, the incidence was 0.55 cases per million inhabitants and year. (If the cases where deadly force was used $(n=19)$ are excluded, the incidence was 0.49 .) Due to methodological problems, the authors point out that the number of cases found might be an underestimate.

In a recent retrospective compilation of deaths in connection with the apprehension of agitated persons in Sweden during the years 1985-2009 [2], the frequency of these deaths was approximately 0.14 per million inhabitants and year. Although this figure could be an underestimate, due to many methodological problems, it does suggest that these deaths are rare events in Sweden, and that they are more uncommon than in the USA.

Hall et al. has made a prospective study of the outcomes of police use of force in a city of over 1.1 million citizens during a three year period, and there was one death during that period [3].

\section{EXCITED DELIRIUM}

In a review of the literature, Vilke et al. [4] compiled the features reported in different case series of excited delirium (ED). The core symptoms of ED are an acute onset of confusion (delirium) in combination with psychomotor and physiological excitation. In addition, many people with ED were reported to have hyperthermia, significant resistance to physical restraint, a history of psychostimulant abuse, and sudden collapse after restraint. In half of the 18 reviewed articles, drug screening for psychostimulants was positive. The review by Vilke et al. was conducted by an American College of Emergency Physicians Task Force in order to clarify whether the entity ED exists as a separate disease.

The concept of ED is sometimes used by forensic pathologists to explain sudden deaths during apprehension, but it has also been argued by some that ED is used to conceal police brutality (Sullivan L. (2007) Death by excited delirium: diagnosis or coverup? National Public Radio, All Things Considered. http://www.npr.org/templates/story/story.php?storyld=7608386. Accessed 2012-12-03) [5]. However, Vilke et al. concluded that ED (or excited delirium syndrome, which is the term that they used) "is a real syndrome with uncertain, likely multiple, etiologies."

As mentioned above, hyperthermia is often encountered in ED. In this context, it is interesting to note that some studies have shown disorders in the dopamine system of deceased people with cocaine-induced ED that differ from dopamine disorders seen in cocaine-overdose victims without signs of preterminal ED. Staley et al. compared dopamine receptors in cocaine-overdose deaths (COD) without signs of preterminal ED, cocaineinduced ED cases, and control subjects [6]. Compared to both control 
subjects and COD, the ED subgroup had a decreased density of D2 receptors in the thermoregulatory center of the hypothalamus. The D1 receptors mediate increases in temperature, while the $\mathrm{D} 2$ receptors mediate decreases. Since the D1 receptors in the thermoregulatory center were unaltered, Staley speculates that a decrease in D2 receptors may explain the malignant hyperthermia associated with ED.

Reuptake of dopamine in the synapses is mediated through the dopamine transporter protein (DTP). Staley et al. [7] showed that chronic cocaine users had a higher density of high-affinity cocaine-recognition sites on DTP. According to Staley, this might represent a compensatory mechanism for the elevated intrasynaptic levels of dopamine caused by cocaine abuse. When comparing control subjects with chronic cocaine users with and without ED, Mash et al. [8] noted an increase in the ventral striatum of high-affinity cocaine-recognition sites in chronic cocaine users without ED, but a decrease in chronic cocaine users with ED. Among the ED cases in this study, there were also four persons without any known history of substance abuse, and they showed a similar decrease in high-affinity cocaine-recognition sites on DTP. They concluded that a combination of measurement of recognition sites and measurement of a heat shock protein together with the descriptions of the decedents' behavior, could serve as a reliable forensic tool for identifying ED at autopsy. Mash et al. suggest that a failure to upregulate the function of DTP and thereby compensate for the increased dopamine release following cocaine abuse may be an underlying mechanism of the development of ED. The results of the study seem to be in good accordance with this theory. However, it might have been better to use hyperthermic patients as controls to exclude the possibility that hyperthermia itself affects the results of measuring cocaine recognition sites.

\section{POSITIONAL ASPHYXIA}

The term positional asphyxia has traditionally been used for deaths in which the decedent was in a body position that he or she could not get out of, and the body position impaired breathing to the extent that death followed from asphyxia [9]. An example is a heroin-intoxicated person who falls asleep with the neck flexed, thereby obstructing the airway. In the last decades, the term has also been used in discussions about the possible contribution of body position to death when a person has been restrained; for example, during a police arrest.

The term traumatic asphyxia denotes cases in which a heavy object exerts pressure on the thorax or abdomen, which prevents adequate breathing movements and thereby prevents adequate gas exchange in the lungs. An example of this is a person who gets stuck under a car when the jack gives way. A common autopsy finding in deaths due to traumatic asphyxia is petechial bleedings in the conjunctiva and/or facial skin. In one case series $(n=32)$ this was present in $72 \%$ of the cases [2].

If a person is apprehended in a prone position with people pushing him or her down to the ground, elements of both positional and traumatic asphyxia might be present. In several case series, the descriptions indicate that both types of asphyxias could have occurred [10]. Despite this, the terms used for these situations are mostly positional or restraint asphyxia.

In many studies and case reports, a body position is described in which the person lies prone with the hands and feet tied together behind the back. Different terms are used for this position, most commonly hog-tie, hobble restraint, or prone maximal restraint position. For the sake of clarity, we will in the remainder of the article refer to this position as prone maximal restraint position (PMRP).

Over the last few decades, there has been a somewhat polarized debate about the existence and significance of positional asphyxia during arrests. The debate seems to have been launched after the publication of an article by Reay et al. [11].In this study, ten healthy subjects exercised until their pulse reached 120 beats/minute (mild effort). The subjects then recovered in a sitting position (control), and after a second effort they recovered in PMRP. The conclusion was that PMRP prolonged the recovery time for pulse and oxygen saturation, and that "positional restraints and its effects should be considered when investigating deaths in persons who were handcuffed in the prone position." One major objection to the study was that they reported that arterial oxygen saturation drops to $85-90 \%$ during exercise and recovery. This contradicts physiology textbooks, which state that oxygen transport in the lungs is primarily perfusion limited except in some elite athletes who, during maximal exercise, can experience a decrease in arterial oxygen content [12]. The low values may have been caused by an unsuitable method for measuring arterial oxygen saturation in exercising persons (ear lobe probe). Subsequent studies have not been able to reproduce the results concerning oxygen saturation found by Reay et al. [13-15].

Chan et al. [13] performed pulmonary function testing (PFT) in healthy subjects in the body positions of sitting, supine, prone, and PMRP. The subjects conducted two episodes of exercise after which they recovered in the sitting position and then PMRP. There was no effect of PMRP on recovery with regard to oxygen saturation or pulse, and no tendency toward carbon dioxide accumulation. For lung function, they noted statistically significant decreases (compared to sitting position) in forced vital capacity (FVC), forced expiratory volume in one second (FEV1), and maximal voluntary ventilation (MVV) in the supine position, prone position, and PMRP. The most pronounced decrease was a $23 \%$ decline in MVV in the PMRP. Since PFT measurements as low as $80 \%$ of predicted values are considered clinically normal, Chan concluded that these changes were statistically significant but not clinically relevant for a healthy, non-intoxicated person. An objection to this conclusion is that predicted values are based on normal variations in a population. An individual could however hypothetically be clinically affected by a reduction in his or her MVV by, for example, 23\%; different people have different capacities and needs. Although they did not find any signs of hypoxia or hypercapnia in this study, a reduction in MVV of this size could well be clinically significant for individuals in situations in which intense struggling occurs. Another study of mean MVV in PMRP showed a reduction of $18 \%$ compared to the sitting position [16].

Schmidt and Snowden [14] measured oxygen saturation and heart rate recovery post-exercise in both PMRP and seated unrestrained (control) . No statistically significant differences were found for pulse recovery. Small but significant changes were found for oxygen saturation; however, all measurements were in the $95-99 \%$ interval.

Parkes performed a study using a methodology based on that reported by Reay et al., with appropriate enhancements $[11,15]$. Parkes did not find any statistically significant influence on pulse recovery when comparing the sitting position with the prone or supine "control and restraint position" (which was not specified more precisely), respectively. However, there was a small but statistically significant increase in pulse recovery in the prone position compared to the supine. No statistically significant differences were noted concerning oxygen saturation. Parkes concluded that there are 
multiple sources of evidence to suggest that restraint in the prone position may affect breathing more than restraint in the supine position and that the restraint position should be considered as a factor in investigations of sudden death during restraint. However, other than a reference to Chan et al's [13] experiment, case reports and observational studies, they did not offer any references supporting this statement. Case reports are generally of low value as evidence. Particularly in cases of death during apprehension, it is virtually impossible to draw any conclusions concerning the causality between prone position and death, since in most apprehensions of agitated people, the apprehended end up in a prone position. Furthermore, in referring to Chan's study, Parkes stated that FVC and FEV1 showed reductions in the supine position and further reductions in the prone position. However, Chan states in his article that there were no statistical differences in these parameters between the prone and the supine position. Therefore, this reference cannot be considered to support Parkes' conclusion about restraint in supine and prone positions.

In another study by Parkes and Carson [17], the spirometric results in four different restraint positions were compared to those in the standing position. In the most restrained position (prone with arms and legs restrained in flexed position; "figure four leg lock"), the mean FVC was reduced by $27.4 \%$. One participant showed a $57 \%$ reduction in FEV1, which was interpreted as a possible worst-case scenario that might occur in real-life incidents.

\section{METABOLIC ACIDOSIS}

A possible role for metabolic acidosis is not always taken into account in case reports of ED-related deaths, and often measurements of $\mathrm{pH}$ and lactate are missing. Hick et al. [18] presented five cases of cardiovascular collapse in people who were struggling despite maximal restraint techniques. The case descriptions raise the suspicion of ED in three of the cases. All five developed a pronounced acidosis with $\mathrm{pH}$ ranging from 6.25 to 6.81 , which was interpreted as lactate acidosis. All were positive for cocaine in urine or blood, and one survived (he had an initial pH of 6.46). Hick concluded that the lactate level documented in one case $(>24 \mathrm{mmol} / \mathrm{L}$ ) was much higher than what has been reported as the top levels in sprinting athletes (17 mmol/L). A study by Bruce et al. [19] of metabolic responses in male athletes with different types of maximal exercise found that they reached excess lactate levels of 7.9-10.7 mmol/L on average. Another case report of severe acidosis [20] during ED and use of cocaine presented a man with a $\mathrm{pH}$ of 6.53 , but who survived after treatment including hyperventilation and sodium bicarbonate.

Ho et al. [21] performed an experimental study on the response in test subjects to different situations that simulated use of force by law enforcement personnel. These situations included both intense physical activity and exposure to an electronic control device and oleoresin capsicum ("pepper spray"). The lowest recorded $\mathrm{pH}$ was in the group who did heavy bag resistance for 45 seconds; the median $\mathrm{pH}$ was 7.01 and the minimum was 6.91 both 2 and 4 minutes post-exposure. The same group also experienced the highest lactate levels with a median of $18.26 \mathrm{mmol} / \mathrm{L}$ at 8 minutes postexposure. Evidently, even short periods of intense physical activity can lead to low $\mathrm{pH}$ values, which makes the profound acidosis attained in cocaineintoxicated people with ED after an intense struggle more understandable. It is also interesting to note that the $\mathrm{pH}$ minimum and lactate maximum in Ho et al.'s study was obtained some minutes after the physical activity ceased, comparable to the minutes after a struggling person has been apprehended and finally calmed down.

Hick et al. [18] concluded that the $\mathrm{pH}$ values in their cases were considerably lower than what have been reported in ordinary out-ofhospital cardiac arrests (pH 7.20-7.26) [18,22]. Hick speculates that the effects of cocaine and the intense struggle contributed to the severe acidosis through different mechanisms. Central stimulant drugs could increase catecholamine-induced vasoconstriction, thereby increasing lactate levels. Psychosis and delirium can elevate the pain threshold, which could make it possible for the person to exert an abnormal amount of muscular effort. Furthermore, sympathetic output might suddenly be reduced due to catecholamine depletion in the suprarenal glands or because of cessation of struggle. This would result in dilatation of the vessels, and large amounts of lactate would stream to the heart with possible arrhythmias as a consequence. Other than a study of burn patients that showed partial or complete depletion of adrenaline and noradrenaline in the adrenal medulla at autopsy [23], we have not found any other references concerning catecholamine depletion in humans.

\section{THE POSSIBLE ROLE OF POSITIONAL ASPHYXIA IN ACIDOSIS DEVELOPMENT}

Since it is impossible to create realistic human experiments to determine how death might occur during apprehensions of agitated people, we are left with the possibility of separately investigating different aspects and then trying to integrate these into scenarios that make pathophysiological sense. One of the key questions that cannot be satisfactorily examined in human experiments is whether the effects on respiration demonstrated in some studies of restraint techniques have any part in the development of the profound acidosis described in case reports.

In some sports, a training method that includes breathing at a reduced frequency during exercise is used in order to induce periods of tissue hypoxia, with the aim of improving lactic acid tolerance. As a consequence, there are several studies of this method in the sports science literature. Although breathing in these studies is reduced by frequency of breaths in contrast with the restrictive respiratory impairment in restrained people, the results may be interesting in the discussion of positional asphyxia and acidosis.

Yamamoto et al. [24] studied the effects of reduced frequency breathing (RFB) on arterial hypoxemia during exercise. The subjects alternated 30 seconds of exercise (bicycle ergometer at $210 \mathrm{~W}$ ) with 30 seconds of rest for ten rounds. This was done both during continuous breathing (CB) and during RFB consisting of breathing cycles with 4 seconds of breath holding at functional residual capacity (FRC) followed by 2 seconds of $C B$. During rest periods, breathing was uncontrolled. The mean pulmonary ventilation during exercise was reduced by $35-45 \%$ with RFB compared to $C B$, while almost the inverse relationship was observed during rest, thereby compensating for the reduced ventilation in RFB. The mean oxygen saturation dropped to $89 \%$ during part of the exercise with RFB, while it was above $96 \%$ at all times with CB. A drop in mean $\mathrm{pH}$ to a lowest value of 7.26 was also noted with RFB. However, lactate was not statistically significantly altered with RFB compared to CB. To investigate this finding further, Yamamoto et al. [25] conducted another study in which they measured lactate during both exercise and recovery phases. They concluded that exercise with RFB probably enhances 
muscle lactate production, but that there is a delay in the appearance of lactate in blood due to an accumulation of lactate in the muscles.

Whether Yamamoto's results have any relevance for the relationship between positional asphyxia and metabolic acidosis in deaths during apprehension is unclear. However, it is interesting to note that a reduction of less than half of the pulmonary ventilation had clinically significant effects on oxygenation and $\mathrm{pH}$.

\section{CHRONIC AND ACUTE ABUSE OF CENTRALSTIMULATING DRUGS}

In case series of deaths in custody or during apprehension with signs of $E D$, many of the deceased show signs of acute and/or chronic abuse of stimulating drugs, most commonly cocaine $[26,27]$. In a Swedish case series the dominating drug was instead amphetamine being present in $53 \%$ of the cases, and no case positive for cocaine [2]. This is probably due to a different pattern of drug use in Sweden, with amphetamine being more common than in many other countries. Grant's report [26] noted positive toxicology (most commonly cocaine, but also PCP) in $71 \%$ of the people who died from ED. In this group of people with ED ( $n=21)$, restraints were used in $86 \%$. Karch states that common autopsy findings in these deaths are mild-to-moderate cardiac enlargement, myocardial fibrosis, and coronary artery disease [27]. These changes can be seen after chronic cocaine abuse [28,29]. If these types of autopsy findings are present, they could be considered the primary cause of death or important factors that contributed to death. As mentioned above, chronic cocaine use can also alter the dopamine system in the brain, which in turn might predispose people toward developing ED. However, chronic cocaine use is not necessary for developing ED and subsequently death. Other possible underlying conditions can be psychosis, brain damage, or mental retardation. In the study by Mash et al. [8], four subjects developed preterminal ED without a history of drug abuse.

\section{AUTONOMIC INSTABILITY}

Another theory that has been discussed in connection with the effect of body position on vital parameters is the so-called Bezold-Jarisch reflex (BJR) [30]. BJR causes the triad of bradycardia, hypotension, and peripheral vasodilatation. BJR is triggered by mechanical or chemical stimulation of afferent vagal fibers in the heart chambers [31]. These vagal fibers exercise a central tonic inhibition to the vasomotor centers, which is increased when $\mathrm{BJR}$ is activated. BJR and the baroreceptors (BR) in the carotid sinuses and aorta interact in blood pressure regulation, normally with $B R$ as the dominant system. In laboratory animals, stimulation with alkaloids can lead to BJR becoming the dominant system, thus causing the symptom triad. However a direct physiological stimulus that causes the same BJR dominance has not been found [31]. In severe hypovolemia, bradycardia can occur; this could possibly be explained by BJR being stimulated through violent heart contractions in poorly filled chambers. The physiological purpose of this might theoretically be that a slower heart rate would allow for a larger blood volume in the chambers and thereby better contractility in accordance with Starling's law.

Roeggla et al. [30] measured FEV1, FVC, blood pressure, heart rate, cardiac output, oxygen saturation, and end tidal carbon dioxide in subjects in both PMRP and upright maximal restraint positions (UMRP). The two restraint positions were compared to control values obtained when the subjects were seated upright without restraints. There was no statistically significant change in UMRP values compared to those obtained in the control position. After 3 minutes in PMRP, there was no change in oxygen saturation, an increase in end tidal carbon dioxide, and quite dramatic decreases in all other parameters. For example, the FVC decreased by $40 \%$, the systolic blood pressure by $32 \%$, the heart rate by $21 \%$, and the cardiac output by $37 \%$. Roeggla speculated that the decrease in blood pressure and cardiac output could be explained by reduced venous return due to elevated intrathoracic pressure, and the decrease in heart rate could be explained by the BJR. They concluded that their data "clearly indicate, that hobble restraint in the prone position leads to a dramatic impairment of hemodynamics and respiration".

\section{OTHER POSSIBLE PATHOGENESIS AND RISK FACTORS}

In some cases, organic pathology, such as heart enlargement, heart fibrosis or coronary sclerosis, might contribute to, or be the main cause, of death. Some claim that an abnormal heart is found in virtually all cases, if the heart is appropriately examined [28]. Otahbachi et al. [32] speculate that these deaths might be explained by a strong sympathetic stress caused by physical exertion, the use of restraints, drug intoxication, and possibly underlying psychiatric disease, all together causing a so called TakoTsubo cardiomyopathy. Tako-Tsubo cardiomyopathy (also named apical ballooning syndrome or stress-induced cardiomyopathy) is a reversible ailment that is often triggered by emotional or physical stress and is manifested as hypokinesia or akinesia in the middle or apical segment of the left ventricle [33]. The pathophysiology is not known, but is thought to be a massive surge of catecholamines. The symptoms mimic an acute coronary syndrome. According to Prasad et al., the vast majority of patients suffering from Tako-Tsubo cardiomyopathy are women above 50 years of age, and the mortality is very low. This suggests that Tako-Tsubo cardiomyopathy alone cannot explain the majority of deaths that occur during apprehension of agitated persons.

In order to identify risk factors of deaths during apprehensions of people with ED, Stratton et al. [34] reported 216 cases of ED where PMRP was used, and among these 20 died (of whom two were removed from the study because the autopsy revealed signs of violence against the neck and lung embolism, respectively). In decreasing order, the identified risk factors were forceful struggle, stimulant drug use (positive toxicology), established natural disease, and obesity.

\section{CONCLUSIONS}

The pathophysiology of deaths that occur during apprehensions of agitated persons is evidently a complex matter. Research carried out over the last few decades has identified different components that might play a role. These include the chronic and acute effects of central stimulants on the brain and heart, ED, metabolic acidosis, positional asphyxia, and autonomic instability. However, the pathophysiology of individual cases most probably differs in that each contains different proportions of one or several of these components. It is our belief that we will not find a unifying pathophysiology for these deaths. Instead, each case will have to be evaluated separately based on the current state of knowledge. 
(2)

Among the proposed factors behind these deaths, there is one that is particularly controversial and for which various studies have yielded diverse results and conclusions, namely positional asphyxia. Many studies have found some impairment in respiration, but come to the conclusions that these impairments are probably not clinically relevant. However, because experimental conditions are so far removed from what occurs in real life, these conclusions are questionable. Furthermore, perhaps researchers should not focus on oxygen saturation alone, but also on ways in which the removal of accumulated carbon dioxide is affected. Since profound acidosis seems to be common in these cases, compensatory hyperventilation may be imperative. Perhaps ventilation in the prone position is sufficient to oxygenize the blood, but not to produce a sufficient compensatory respiratory alkalosis in a profound metabolic acidosis?

Based on the current studies and case reports of deaths during the apprehension of agitated people, our interpretation is that some factors related to prolonged and intense struggle, for example acidosis, seem to be of importance, while body position alone does not seem to be a major causative factor. However, it might very well be a contributing factor, suggesting that the choice of an adequate but safe restraint technique could prevent some of these deaths. We believe that the most important next step is to further investigate the possible relationship between body position and acidosis, hypoxia and hypercapnia, using different and more realistic conditions than in previous studies.

\section{ACKNOWLEDGEMENTS}

This study was financially supported by the Swedish National Board of Forensic Medicine.

\section{CONFLICT OF INTEREST}

The authors have no conflict of interest.

\section{REFERENCES}

[1] Ho, J. D., Heegaard, W. G., Dawes, D. M., Natarajan, S., Reardon, R. F., \& Miner, J. R. (2009, May). Unexpected arrest-related deaths in america: 12 months of open source surveillance. West J Emerg Med, 10(2), 68-73 Medline.

[2] Thiblin, I. Dödsfall vid polisingripande. Riskfaktorer och rekommendationer. (Deaths during police arrest. Risk factors and recommendations.), Polishögskolans serie i polisiärt arbete, April 2011 edn, Polishögskolan, Solna, Stockholm, 2011

[3] Hall, C. A., McHale, A. M. D., Kader, A. S., Stewart, L. C., MacCarthy, C. S., \& Fick, G. H. (2012, February). Incidence and outcome of prone positioning following police use of force in a prospective, consecutive cohort of subjects. Journal of Forensic and Legal Medicine, 19(2), 83-89. doi:10.1016/j.jflm.2011.12.008. Medline

[4] Vilke, G. M., DeBard, M. L., Chan, T. C., Ho, J. D., Dawes, D. M., Hall, C., et al. (2012, November). Excited Delirium Syndrome (ExDS): defining based on a review of the literature. The Journal of Emergency Medicine, 43(5), 897-905. doi:10.1016/j. jemermed.2011.02.017. Medline

[5] Paquette M., Excited delirium: Does it exist?, Perspect Psychiatr C, 2003, 39, 93-94

[6] Staley, J. K., Wetli, C. V., Ruttenber, A. J., Hearn, W. L., \& Mash, D. C. (1995). Altered dopaminergic synaptic markers in cocaine psychosis and sudden death. NIDA Research Monograph, 153, 491.

[7] Staley, J. K., Hearn, W. L., Ruttenber, A. J., Wetli, C. V., \& Mash, D. C. (1994, December). High affinity cocaine recognition sites on the dopamine transporter are elevated in fatal cocaine overdose victims. The Journal of Pharmacology and Experimental Therapeutics, 271(3), 1678-1685 Medline.

[8] Mash, D. C., Duque, L., Pablo, J., Qin, Y., Adi, N., Hearn, W. L., et al. (2009, September). Brain biomarkers for identifying excited delirium as a cause of sudden death. Forensic Science International, 190(1-3), e13-e19. doi:10.1016/j. forsciint.2009.05.012. Medline

[9] Bell, M. D., Rao, V. J., Wetli, C. V., \& Rodriguez, R. N. (1992). Positional asphyxiation in adults. A series of 30 cases from the Dade and Broward County Florida Medical Examiner Offices from 1982 to 1990. The American Journal of Forensic Medicine and Pathology, 13(2), 101-107. doi:10.1097/00000433-199206000-00004. Medline
[10] O'Halloran, R. L., \& Lewman, L. V. (1993). Restraint asphyxiation in excited delirium. The American Journal of Forensic Medicine and Pathology, 14(4), 289295. doi:10.1097/00000433-199312000-00004. Medline

[11] Reay, D. T., Howard, J. D., Fligner, C. L., \& Ward, R. J. (1988). Effects of positional restraint on oxygen saturation and heart rate following exercise. The American Journal of Forensic Medicine and Pathology, 9(1), 16-18. doi:10.1097/00000433-198803000-00005. Medline

[12] Boron, W. F., \& Boulpaep, E. L. Medical physiology : a cellular and molecular approach, 1st edn, W.B. Saunders, Philadelphia, PA, 2003

[13] Chan, T. C., Vilke, G. M., Neuman, T., \& Clausen, J. L. (1997, November). Restraint position and positional asphyxia. Annals of Emergency Medicine, 30(5), 578-586. doi:10.1016/S0196-0644(97)70072-6. Medline

[14] Schmidt, P., \& Snowden, T. (1999, September). The effects of positional restraint on heart rate and oxygen saturation. The Journal of Emergency Medicine, 17(5), 777-782. doi:10.1016/S0736-4679(99)00083-9. Medline

[15] Parkes, J. (2000, January). Sudden death during restraint: a study to measure the effect of restraint positions on the rate of recovery from exercise. Medicine, Science, and the Law, 40(1), 39-44 Medline.

[16] Michalewicz, B. A., Chan, T. C., Vilke, G. M., Levy, S. S., Neuman, T. S., \& Kolkhorst, F. W. (2007, January). Ventilatory and metabolic demands during aggressive physical restraint in healthy adults. Journal of Forensic Sciences, 52(1), 171-175. doi:10.1111/j.1556-4029.2006.00296.x. Medline

[17] Parkes, J., \& Carson, R. (2008, April). Sudden death during restraint: do some positions affect lung function? Medicine, Science, and the Law, 48(2), 137-141. doi:10.1258/rsmmsl.48.2.137. Medline

[18] Hick, J. L., Smith, S. W., \& Lynch, M. T. (1999, March). Metabolic acidosis in restraint-associated cardiac arrest: a case series. Acad Emerg Med, 6(3), 239-243. doi:10.1111/j.1553-2712.1999.tb00164.x. Medline

[19] Bruce, R. A., Jones, J. W., \& Strait, G. B. (1964, May). Anaerobic metabolic responses to acute maximal exercise in male athletes. American Heart Journal, 67(5), 643650. doi:10.1016/0002-8703(64)90335-7. Medline

[20] Allam, S., \& Noble, J. S. (2001, April). Cocaine-excited delirium and severe acidosis. Anaesthesia, 56(4), 385-386. doi:10.1046/j.1365-2044.2001.01976-24.x. Medline 
[21] Ho, J. D., Dawes, D. M., Nelson, R. S., Lundin, E. J., Ryan, F. J., Overton, K. G., et al. (2010, July). Acidosis and catecholamine evaluation following simulated law enforcement "use of force" encounters. Acad Emerg Med, 17(7), e60-e68. doi:10.1111/j.1553-2712.2010.00813.x.

[22] Dybvik, T., Strand, T., \& Steen, P. A. (1995, April). Buffer therapy during outof-hospital cardiopulmonary resuscitation. Resuscitation, 29(2), 89-95. doi:10.1016/0300-9572(95)00850-S. Medline

[23] Goodall, C. M. (1967, January). Sixth National Burn Seminar. Sympatho-adrenal medullary response to thermal injury. The Journal of Trauma, 7(1), 144-147 Medline.

[24] Yamamoto, Y., Mutoh, Y., Kobayashi, H., \& Miyashita, M. (1987). Effects of reduced frequency breathing on arterial hypoxemia during exercise. European Journal of Applied Physiology and Occupational Physiology, 56(5), 522-527. doi:10.1007/ BF00635364. Medline

[25] Yamamoto, Y., Takei, Y., Mutoh, Y., \& Miyashita, M. (1988, March). Delayed appearance of blood lactate with reduced frequency breathing during exercise. European Journal of Applied Physiology and Occupational Physiology, 57(4), 462-466. doi:10.1007/BF00417994. Medline

[26] Grant, J. R., Southall, P. E., Mealey, J., Scott, S. R., \& Fowler, D. R. (2009). Excited delirium deaths in custody. The American Journal of Forensic Medicine and Pathology, 30(1), 1-5. doi:10.1097/PAF.0b013e31818738a0. Medline

[27] Karch, S. B., \& Stephens, B. G. (1999, March). Drug abusers who die during arrest or in custody. Journal of the Royal Society of Medicine, 92(3), 110-113 Medline.
[28] Karch, S. B. Karch's pathology of drug abuse, 4th edn, CRC Press, Boca Raton, 2009

[29] Stephens, B. G., Jentzen, J. M., Karch, S., Mash, D. C., \& Wetli, C. V. (2004). Criteria for the interpretation of cocaine levels in human biological samples and their relation to the cause of death. The American Journal of Forensic Medicine and Pathology, 25(1), 1-10. doi:10.1097/01.paf.0000118960.58334.a9. Medline

[30] Roeggla, M., Wagner, A., Muellner, M., Bur, A., Roeggla, H., Hirschl, M. M., et al. (1997, May 23). Cardiorespiratory consequences to hobble restraint. Wiener Klinische Wochenschrift, 109(10), 359-361 Medline.

[31] Warltier, D. C., Campagna, J. A., \& Carter, C. (2003). Clinical relevance of the Bezold-Jarisch reflex. Anesthesiology, 98(5), 1250-1260. doi:10.1097/00000542200305000-00030. Medline

[32] Otahbachi, M., Cevik, C., Bagdure, S., \& Nugent, K. (2010). Excited delirium, restraints, and unexpected death. The American Journal of Forensic Medicine and Pathology, 31(2), 107-112. doi:10.1097/PAF.0b013e3181d76cdd. Medline

[33] Prasad, A., Lerman, A., \& Rihal, C. S. (2008, March). Apical ballooning syndrome (Tako-Tsubo or stress cardiomyopathy): A mimic of acute myocardial infarction. American Heart Journal, 155(3), 408-417. doi:10.1016/j.ahj.2007.11.008. Medline

[34] Stratton, S. J., Rogers, C., Brickett, K., \& Grunzinski, G. (2001, May). Factors associated with sudden death of individuals requiring restraint for excited delirium. The American Journal of Emergency Medicine, 19(3), 187-191. doi:10.1053/ajem.2001.22665. Medline[ 